\title{
Younger Al-Mg ages of chondrules in CO chondrites than $\mathrm{L} / \mathrm{LL}$ chondrites
}

\author{
N. T. KITA ${ }^{1 *}$, K. FUKUDA ${ }^{1}$, G. SIRON ${ }^{1}$, AND M. KIMURA ${ }^{2}$
}

${ }^{1}$ WiscSIMS, Univ. Wisconsin-Madison, Madison, WI 53706, USA (*correspondence: noriko@geology.wisc.edu)

${ }^{2}$ National Institute of Polar Research, Tachikawa, Tokyo 1908518, Japan

\section{Introduction}

The ${ }^{26} \mathrm{Al}-{ }^{26} \mathrm{Mg}$ chronology (half-life: $0.7 \mathrm{Ma}$ ) has been used to determine the relative formation time of chondrules with high precision $(\leq 0.1 \mathrm{Ma}$ [1]). [2] reported that chondrules in Y-81020 (CO3.05) have the inferred initial $\left({ }^{26} \mathrm{Al} /{ }^{27} \mathrm{Al}\right)_{0}$ ratios of $(3-10) \times 10^{-6}$, similar to those in ordinary chondrites. These data are systematically higher than those of Acfer 094 (ungroup C3.00) and Kaba (CV3) chondrites with values from (4-6) $\times 10^{-6}$ [3-5]. Here, we selected four chondrules in [2] and reanalzyed their Al-Mg isotope system by using WiscSIMS IMS 1280 . We have significantly improved accuracy of $\mathrm{Mg}$ isotope analyses by using multicollection Faraday Cups [6]. We test if chondrules in CO formed earlier than those in other carbonaceous chondrites.

\section{Results and Discussions}

Results obtained from four type I (FeO-poor) chondrules show $\left({ }^{26} \mathrm{Al} /{ }^{27} \mathrm{Al}\right)_{0}$ ratios of $(4.6-6.4) \times 10^{-6}$. These values are systematically lower than results in [2], but slightly higher than those of type II (FeO-rich) chondrules in Y-81020 and Acfer $094\left(\sim 4 \times 10^{-6}[4,7]\right)$. We recently reported Al-Mg analyses of chondrules in $\mathrm{L}$ and LL chondrites with inferred $\left({ }^{26} \mathrm{Al} /{ }^{27} \mathrm{Al}\right)_{0}$ ratios of $(6-9) \times 10^{-6}[8]$, which seem to be as much as $0.5 \mathrm{Ma}$ older than those of Y-81020 type I chondrules.

By assuming chondrule formation regions locate from inner to outer disk in the order of OC chondrules < type I in $\mathrm{CO}<$ type II in $\mathrm{CO}$, systematic differences among their inferred $\left({ }^{26} \mathrm{Al} /{ }^{27} \mathrm{Al}\right)_{0}$ may suggests that the location of the chondrule formation region moved from the inner to outer disk in the time period from 1.8 Ma to 2.6 Ma after CAIs. Formation locations might further moved to outer disk until 4 Ma when majority of CR chondrules formed [9-10].

[1] Kita and Ushikubo (2012) Meteorit. Planet. Sci. 47, 11081119. [2] Kurahashi et al. (2008) GCA 72, 3865-3882. [3] Uhsikubo et al. (2013) GCA 109, 280-295. [4] Hertwig et al. (2019) GCA 253, 111-126. [5] Nagashima et al. (2017) GCA 201, 303-319. [6] Siron et al. (2020) LPSC 51, \#1587. [7] Kita et al. (2019) LPSC 50, \#2213. [8] Siron et al. (2020) LPSC 51, \#1574. [9] Schrader et al. (2017) GCA 201, 275302. [10] Tenner et al. (2019) GCA 260, 133-160. 